\title{
Diabetes mellitus is associated with liver metastasis of colorectal cancer through production of biglycan-rich cancer stroma
}

\author{
Rina Fujiwara-Tani ${ }^{1}$, Takamitsu Sasaki ${ }^{1}$, Kiyomu Fujii ${ }^{1}$, Yi Luo ${ }^{1,2}$, Takuya Mori ${ }^{1}$, \\ Shingo Kishi ${ }^{1}$, Shiori Mori' ${ }^{1}$, Sayako Matsushima-Otsuka ${ }^{1}$, Yukiko Nishiguchi' ${ }^{1}$, Kei \\ Goto $^{1}$, Isao Kawahara ${ }^{1}$, Masuo Kondoh ${ }^{3}$, Masayuki Sho ${ }^{4}$ and Hiroki Kuniyasu ${ }^{1}$ \\ ${ }^{1}$ Department of Molecular Pathology, Nara Medical University, Kashihara, Nara 634-8521, Japan \\ ${ }^{2}$ Key Laboratory of Neuroregeneration of Jiangsu and Ministry of Education, Co-Innovation Center of Neuroregeneration, \\ Nantong University, Nantong, Jiangsu Province 226001, China \\ ${ }^{3}$ Drug Innovation Center, Graduate School of Pharmaceutical Sciences, Osaka University, Suita, Osaka 565-0871, Japan \\ ${ }^{4}$ Department of Surgery, Nara Medical University, Kashihara, Nara 634-8522, Japan \\ Correspondence to: Hiroki Kuniyasu, email: cooninh@zb4.so-net.ne.jp
}

Keywords: diabetes; liver metastasis; colorectal cancer; biglycan; mesenchymal stem cell

Received: May 27, 2020

Accepted: June 20, 2020

Published: August 04, 2020

Copyright: Fujiwara-Tani et al. This is an open-access article distributed under the terms of the Creative Commons Attribution License 3.0 (CC BY 3.0), which permits unrestricted use, distribution, and reproduction in any medium, provided the original author and source are credited.

\section{ABSTRACT}

High morbidity and mortality of cancer, especially colorectal cancer (CRC), in diabetic patients have been reported. In this study, we investigated the relationship between the presence of diabetes mellitus (blood hemoglobin A1C was $6.5 \%$ or higher at the time of diagnosis of (RC) and the progression and liver metastasis of CRC. Histopathological findings in the primary lesions, which were preferential to diabetes-complicated CRC (DM-CRC) and the liver metastasis, were also investigated. Of the 473 CRC patients who underwent curative surgical resection, 148 (31\%) had diabetes. In DM-CRC cases, the stage was more advanced, with more cases in stage IV or postoperative disease recurrence. Histopathological findings correlated with liver metastasis in DM-CRC, including budding grade, perineural invasion, and myxomatous tumor stroma, and all were highly correlated with the stage. Additionally, myxomatous stroma showed the strongest correlation with liver metastasis in multivariate analysis. Myxomatous stroma in stage III cases correlated with liver recurrence. The myxomatous stroma was abundant in biglycan protein and contained numerous CD90-positive mesenchymal stem cells (MSCs). In human colon cancer cell line HT29, biglycan expression was induced by high sugar concentration, fatty acids, and insulin, and its contact co-culture with MSCs resulted in enhanced stemness and epithelialmesenchymal transition phenotype. Thus, DM-CRC has higher malignant phenotypes compared to non-DM-CRC, and the involvement of diabetes-induced biglycan may act as a pathogenic factor.

\section{INTRODUCTION}

Diabetes mellitus is a social problem in developed countries due to its frequency and the diversity and severity of its complications. It is estimated that there are about 463 million people with diabetes between the age of 20 and 79 in the world and about 7.39 million in Japan [1]. In recent years, attention has been focused on the relationship between diabetes and cancer, with the latter being one of the various complications observed in patients with diabetes. The incidence of cancer was reported to be higher in diabetic groups than in nondiabetic groups, and the risk of carcinogenesis is increased in early stages of glucose metabolism disorders [2].

People with diabetes have an increased risk of carcinogenesis in most organs [3], including liver, pancreas, colorectum, stomach, breast, lung, oral cavity, and endometrium, and increased risk of associated mortality [2-4]. In particular, pancreatic, liver, and colon cancer are often associated with diabetes $[3,5,6]$. Smoking, diabetes, obesity, and lean meat diet are known as carcinogenic risks in colorectal cancer (CRC) [7]. The 
meta-analysis of 15 studies found that among 2,593,935 patients with $\mathrm{CRC}$, those with diabetes had a hazard ratio of 1.30 and a mortality rate of 1.26 compared to the nondiabetic patients [8]. Conversely, the incidence of diabetes in $\mathrm{CRC}$ is $5-8 \%[9,10]$.

The causes of increased carcinogenic risk in diabetes include increased oxidative stress, high levels of insulin, related growth factors, and its binding factors, insulin receptor substrate-1 and their downstream phosphoinositide 3-kinase (PI3K), AKT, mitogenactivated protein kinase (MAPK) signal, AMP activated kinase (PRKA), mammalian target of rapamycin, sirtuin 1, and autophagy signal activation [2, 4-6, 11-13]. Advanced glycation end-product (AGE), receptor for AGE (RAGE), and high mobility group box-1 (HMGB1) are emphasized as the causes of complications in diabetes [14]. Previously, we reported the promotion of CRC carcinogenesis by AGE-RAGE and HMGB1-RAGE [15, 16]. Furthermore, activation of renin-angiotensin system and aldolase A associated with hyperglycemia promotes CRC progression $[17,18]$. Overexpression of biglycan, a class I small leucine-rich repeat proteoglycan (SLRP), is associated with progression, liver metastasis, recurrence and poor prognosis of CRC $[19,20]$.

Thus, diabetes is considered to be a factor that promotes CRC carcinogenesis and an exacerbation factor. One-fourth of CRC cases with invasion beyond the submucosal layer show liver metastasis during and/or after the operation [21]. One-third of CRC patients died of liver metastasis [22]. Therefore, it is important to elucidate the relationship between diabetes and liver metastasis of CRC. Furthermore, histopathological findings that show the effects of diabetes in CRC or the metastatic ability have not been reported so far. Here, we aimed to clarify the relationship between diabetes and CRC metastasis, especially liver metastasis via histopathological examinations.

\section{RESULTS}

\section{Association of diabetes with liver metastasis in CRC cases}

Clinicopathological factors were compared among the $473 \mathrm{CRC}$ cases that had undergone surgical resection (Table 1). There was no difference in local progression (pT) between the two groups; however, lymph node metastasis $(\mathrm{pN})$ and pStage were more advanced in diabetes mellitus-complicated CRC (DM-CRC). In particular, distant metastases were frequently observed in DM-CRC for all liver, peritoneum, and lung metastases.

\section{Histological findings associated with liver metastasis in DM-CRC}

Histological findings showed that budding, nerve invasion, vascular invasion, lymph vessel invasion, distant invasion, and myxomatous stroma were observed more frequently in DM-CRC than those in non-DM-CRC. As shown in Figure 1, myxomatous stroma was abundant in stromal cells and poor in collagen fibers, and stromal mucus-like weak basophilic deposits were observed. Furthermore, budding grade, nerve invasion, and the myxomatous stroma were significantly associated with pStage in DM-CRC cases with high significance (Table 2). Furthermore, the correlation between clinicopathological factors and liver metastases was examined by multivariate analysis (Table 3). Myxomatous stroma showed the highest correlation, followed by budding grade.

\section{Properties of myxomatous stroma}

The properties of myxomatous stroma were examined by immunostaining (Figure 2). The myxomatous stroma showed biglycan expression and the stromal cells comprised of many CD90-positive mesenchymal stem cells (MSCs). Biglycan expression was observed in all cases of myxomatous stroma, except for one case, but only in $11 \%$ in case of usual stroma (Table 4). In stage IV CRCs, biglycan expression was observed more frequently in liver metastasis cases (93\%) than in non-liver metastasis cases (45\%) (Table 5).

\section{Myxomatous stroma predicted postoperative liver metastasis}

We examined the relationship between myxomatous stroma and postoperative liver metastasis (liver recurrence) in stage III CRC cases (Table 6). Liver recurrence was found in $7(7 \%)$ of 100 cases with usual stroma, whereas it was found in 19 (29\%) of 65 cases with myxomatous stroma. Thus myxomatous stroma might predict liver recurrence in stage III CRCs.

\section{Mesenchymal stem cells (MSCs) in myxomatous stroma}

Next, we examined the number of CD90-positive MSCs in the stroma in the invasive front (Figure 3). The number of CD90-positive MSCs was significantly higher in pStage IV cases and higher in cases with liver metastases (Figure 3A). Compared with the expression of biglycan, there were significantly more MSCs in biglycan $(+)$ cases than in biglycan $(-)$ cases (Figure 3B). Furthermore, comparison between the expression of biglycan and Claudin-4 in cancer cells showed that the expression of Claudin-4 was significantly decreased in biglycan $(+)$ cases (Figure 3C).

\section{Relationship between biglycan and epithelial- mesenchymal transition (EMT) in HT29 cells}

We examined the effect of diabetes-associated factors on biglycan expression in HT29 human colon cancer cells 
Table 1: Comparison of clinicopathological parameters between non-DM-CRC and DM-CRC

\begin{tabular}{|c|c|c|c|c|}
\hline Parameter & & Non-diabetic CRC & Diabetic CRC ${ }^{1}$ & $P^{4}$ \\
\hline$N$ & & 325 & 148 & \\
\hline \multirow[t]{2}{*}{ Sex } & Male & 177 & 75 & NS \\
\hline & Female & 148 & 73 & \\
\hline Age & & $71(38-93)$ & $72(40-95)$ & NS \\
\hline \multirow[t]{2}{*}{ Location } & Right & 119 & 54 & NS \\
\hline & Left & 206 & 94 & \\
\hline \multirow[t]{2}{*}{ Histology ${ }^{2}$} & Differentiated & 293 & 133 & NS \\
\hline & Undifferentiated & 32 & 15 & \\
\hline \multirow[t]{3}{*}{$\mathrm{pT}^{2}$} & 2 & 42 & 25 & NS \\
\hline & 3 & 219 & 92 & \\
\hline & 4 & 64 & 31 & \\
\hline \multirow[t]{2}{*}{$\mathrm{pN}^{2}$} & 0 & 182 & 61 & 0.0030 \\
\hline & $1-2$ & 143 & 87 & \\
\hline \multirow[t]{3}{*}{ Stage $^{2}$} & I-II & 170 & 50 & 0.0015 \\
\hline & III & 106 & 59 & \\
\hline & IV & 49 & 39 & \\
\hline \multirow[t]{3}{*}{ Distant metastasis } & Liver & 31 & 30 & 0.0018 \\
\hline & Peritoneum & 5 & 12 & 0.0008 \\
\hline & Lung & 2 & 9 & 0.0007 \\
\hline \multirow[t]{2}{*}{ Recurrence } & Negative & 314 & 130 & 0.001 \\
\hline & Positive & 11 & 18 & \\
\hline \multirow[t]{3}{*}{ Budding grade ${ }^{3}$} & 1 & 26 & 7 & 0.0002 \\
\hline & 2 & 157 & 45 & \\
\hline & 3 & 142 & 96 & \\
\hline \multirow[t]{2}{*}{$\mathrm{Pn}^{3}$} & 0 & 236 & 88 & 0.0055 \\
\hline & 1 & 89 & 60 & \\
\hline \multirow[t]{2}{*}{$\mathrm{Ly}^{3}$} & 0 & 169 & 56 & 0.0054 \\
\hline & 1 & 156 & 92 & \\
\hline \multirow[t]{2}{*}{$\mathrm{V}^{3}$} & 0 & 181 & 61 & 0.0040 \\
\hline & 1 & 144 & 87 & \\
\hline \multirow[t]{2}{*}{$E^{3}$} & 0 & 245 & 98 & 0.0455 \\
\hline & 1 & 80 & 50 & \\
\hline \multirow[t]{2}{*}{ Stroma } & Usual & 245 & 69 & 0.0002 \\
\hline & Myxomatous & 80 & 79 & \\
\hline
\end{tabular}

${ }^{1}$ Blood hemoglobin A1C was equal or higher to $6.5 \%$ at the time of colorectal cancer (CRC) diagnosis. ${ }^{2}$ Clinicopathological classification is according to UICC-TNM Classification [61]. Differentiated type, pap, tub1, tub2; Undifferentiated type, por, sig, muc; pT2, tumor invades into muscularis propria layer; pT3, tumor invades into subserosa or adventitia; pT4, tumor exposes to the serosal surface or invades other organ; $\mathrm{pN} 0$, no lymph node metastasis; $\mathrm{pN} 1-2$, metastasis to regional lymph nodes; stage I-II, cases invaded into the submucosal layer or above; stage III, any case with lymph node metastasis; stage IV, any case with or without lymph node metastases but with distant metastases. ${ }^{3}$ Histopathological findings are according to Japanese Classification of Colorectal Carcinoma [62]. Budding grade 1, number of cancer nest of 5 or less cancer cells at the

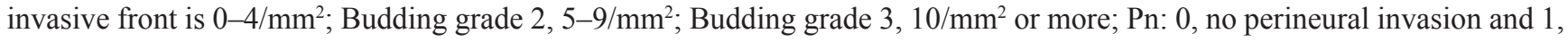
presence of perineural invasion; Ly: 0 , no lymphatic invasion and 1, presence of lymphatic invasion; V: 0 , no venous invasion and 1, presence of venous invasion; Ex: 0 , no extramural cancer deposits without lymph node structure and 1, presence of extramural cancer deposits without lymph node structure. ${ }^{4} \mathrm{P}$ value was calculated by Fisher's exact test or $\mathrm{Chi}^{2}$ test. 
(Figure 4A). Biglycan protein levels were increased in HT29 cells treated with high level of glucose $(450 \mathrm{mg} / \mathrm{dL})$ or the fatty acids, linoleic acid and elaidic acid. Furthermore, simultaneous treatment with insulin synergistically increased the glucose or fatty acid treatment-induced biglycan levels.

Alteration in the expression of EMT-associated proteins was examined when HT29 cells were cocultured with human MSCs and biglycan was knocked down (Figure 4B). In co-culture conditions where HT29 cells contacted MSCs, biglycan knockdown increased E-cadherin and Claudin-4 expression and decreased Snail and CD44 expression, indicating a reduced EMT phenotype. In contrast, when MSC was placed in an insert chamber and co-cultured with HT29 cells in a noncontact condition, the above alterations in expression were not observed. Biglycan knockdown also decreased cell proliferation in HT29 cells (Figure 4C).
Next, the number of liver metastases was examined when a mixture of HT29 cells and MSCs was inoculated into the spleen of nude mice (Figure 4D). Compared with HT29 alone, the mixed inoculation of HT29 and MSC increased the number of liver metastases by 1.7 fold. In contrast, the mixed inoculation of biglycan knocked down-HT29 cells and MSCs decreased the number of liver metastases to the same level as observed with the inoculation of HT29 alone; this indicated that biglycan knockdown suppressed the effect of the mixed MSCs.

\section{DISCUSSION}

In this study, myxomatous tumor stroma was observed as a histopathological finding that is frequently observed in CRC with diabetes and was shown to have a high correlation with liver metastasis. The myxomatous

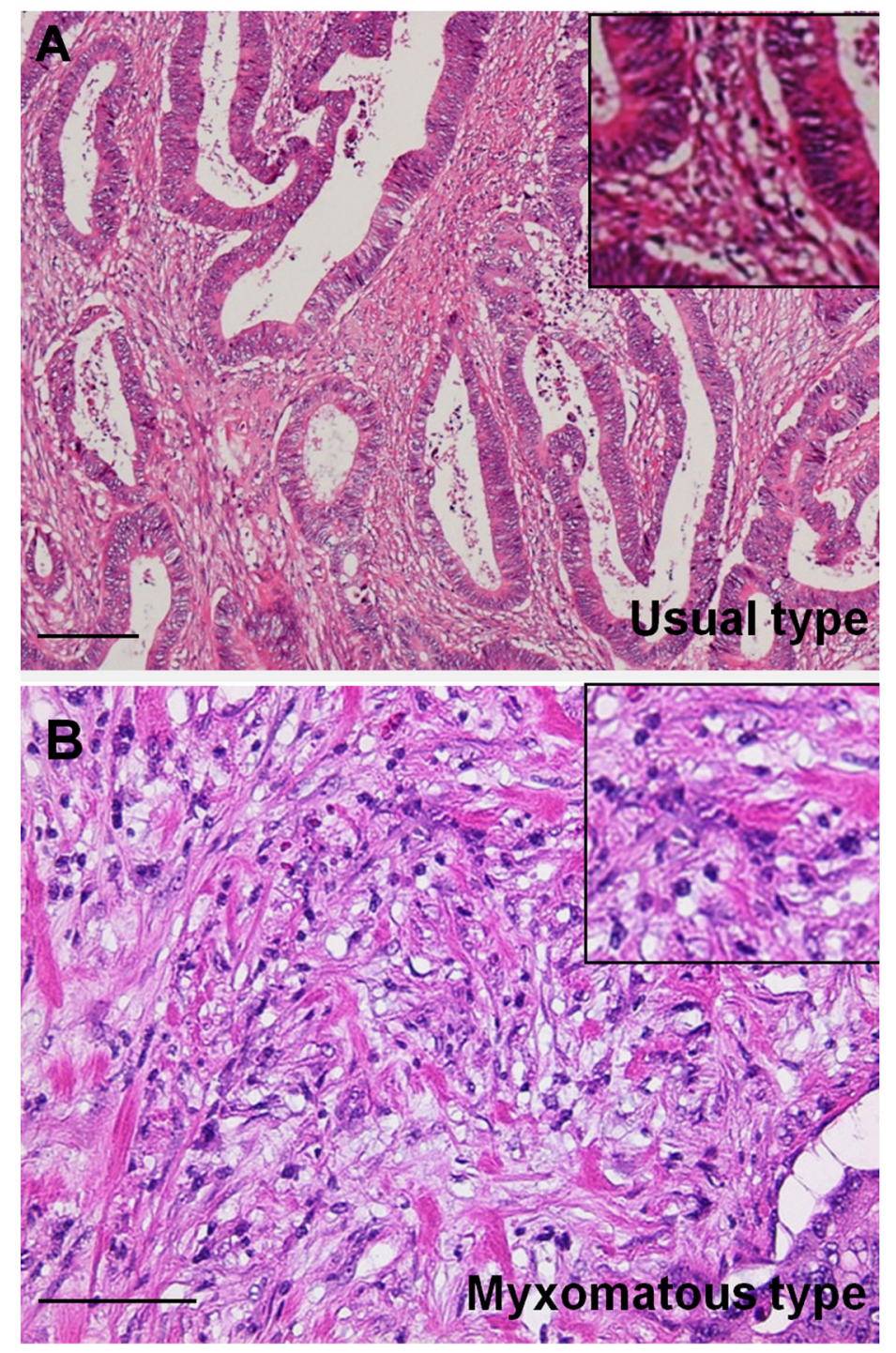

Figure 1: Histopathological findings of myxomatous stroma in colorectal cancer. (A) Usual type stroma with abundant collagenous fibers. (B) Myxomatous type stroma with weak basophilic stroma resembling cartilaginous mucin with abundant small spindle stromal cells. Inset, high magnification image. Hematoxylin and eosin staining. Scale bar: $100 \mu \mathrm{m}$. 
Table 2: Relation of stage with histopathological parameters

\begin{tabular}{lccccc}
\hline & & Stage I-II & Stage III & Stage IV & $P$ \\
\hline$N$ & & 220 & 165 & 88 & \\
Budding grade & $1-2$ & 200 & 35 & 0 & $<0.0001$ \\
& 3 & 20 & 130 & 88 & \\
Pn & 0 & 198 & 113 & 13 & $<0.0001$ \\
\multirow{2}{*}{ Stroma } & 1 & 22 & 52 & 75 & \\
& Usual & 208 & 100 & 18 & $<0.0001$ \\
\hline
\end{tabular}

${ }^{1}$ Clinicopathological classification is according to UICC-TNM Classification [61]. Stage I-II, cases invaded into the submucosal layer or above; stage III, any cases with lymph node metastasis; stage IV, any case with or without lymph node metastases but with distant metastases. ${ }^{2}$ Histopathological findings are according to Japanese Classification of Colorectal Carcinoma [62]. Budding grade 1, number of cancer nest of 5 or less cancer cells at the invasive front is $0-4 / \mathrm{mm}^{2}$; Budding

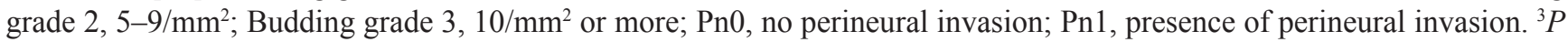
value was calculated by $\mathrm{Chi}^{2}$ test.

Table 3: Multiple regression between liver metastasis and pathological parameters

\begin{tabular}{|c|c|c|c|}
\hline Parameters & Coefficient & $95 \%$ confidential interval & $P^{5}$ \\
\hline Stage $^{1}$ & -0.1729 & $-0.3412-0.004714$ & 0.0438 \\
\hline Subserosal invasion ${ }^{2}$ & 0.002473 & $-0.01050-0.01545$ & 0.706 \\
\hline $\mathrm{Ly}^{3}$ & -0.05134 & $-0.1400-0.03735$ & 0.253 \\
\hline $\mathrm{V}^{3}$ & 0.04475 & $-0.01643-0.1059$ & 0.1494 \\
\hline No. of nodal metastasis & -0.01992 & $-0.04050-0.0006508$ & 0.0573 \\
\hline Budding grade ${ }^{3}$ & 0.1246 & $0.02536-0.2239$ & 0.0143 \\
\hline Myxomatous stroma & 0.1852 & $0.04177-0.3287$ & 0.0118 \\
\hline $\mathrm{Pn}^{3}$ & 0.05314 & $-0.06747-0.1737$ & 0.0384 \\
\hline $\mathrm{Ex}^{3}$ & 0.1869 & $0.03655-0.3373$ & 0.0152 \\
\hline Mucosal hyperplasia ${ }^{4}$ & 0.02277 & $-0.04788-0.09341$ & 0.5236 \\
\hline
\end{tabular}

${ }^{1}$ Pathological stage is according to UICC-TNM Classification [61]. ${ }^{2}$ Distance of subserosal or adventitial invasion from the lower edge of muscularis propria layer (mm). ${ }^{3}$ Histopathological findings are according to Japanese Classification of Colorectal Carcinoma [62]. ${ }^{4}$ Hyperplastic change in the mucosa adjacent to cancer [63, 64]. ${ }^{5} P$ value was calculated by multiple regression analysis using EZR program [60].

Table 4: Association of biglycan with myxomatous stroma

\begin{tabular}{cccc}
\hline Biglycan & Stroma & & $\boldsymbol{P}^{2}$ \\
\cline { 2 - 4 } & Usual & Myxomatous & \\
Negative & 290 & $1(0.3 \%)$ & $<0.0001$ \\
Positive & 36 & $146(80 \%)$ & $<$ \\
\hline
\end{tabular}

${ }^{1}$ When the biglycan expression levels were higher than those in the mucosa adjacent to cancer, it was judged as overexpression positive. ${ }^{2} P$ value was calculated by Fisher's exact test.

stroma was rich in extracellular matrix containing biglycan and CD90-positive MSCs.

Biglycan is a component of the cartilagenous matrix [23]. Biglycan is soluble and causes inflammation and autophagy [24, 25]. The stromal mucin-like findings of the myxomatous stroma upon hematoxylin \& eosin staining was considered to be due to the nature of the biglycan cartilaginous matrix.

It has been reported that biglycan is overexpressed in various cancers and correlates with progression, metastasis, and angiogenesis of gastric cancer, endometrial cancer, prostate cancer, and bladder cancer [26-31]. 
Table 5: Association of biglycan with liver metastasis

\begin{tabular}{lccc}
\hline Biglycan $^{1}$ & \multicolumn{2}{c}{ Liver metastasis in stage IV } & $\boldsymbol{P}^{\mathbf{2}}$ \\
\cline { 2 - 3 } & Negative & Positive & \\
Negative & 17 & 2 & $<0.0001$ \\
Positive & $14(45 \%)$ & $28(93 \%)$ & \\
\hline
\end{tabular}

${ }^{1}$ When the biglycan expression levels were higher than those in the mucosa adjacent to cancer, it was judged as overexpression positive. ${ }^{2} P$ value was calculated by Fisher's exact test.

Table 6: Association of stroma with postoperative liver metastasis in stage III CRCs

\begin{tabular}{lccc}
\hline Stroma & \multicolumn{2}{c}{ Liver metastasis in stage III } & $\boldsymbol{P}^{\mathbf{1}}$ \\
\cline { 2 - 4 } & Negative & Positive & \\
\hline Usual & 93 & $7(7 \%)$ & 0.0003 \\
Myxomatous & 46 & $19(29 \%)$ & 0.000 \\
\hline
\end{tabular}

${ }^{1} P$ value was calculated by Fisher's exact test.

In melanoma, biglycan results in stromal stiffness and integrin activation [32]. Biglycan secreted from tumor vascular endothelial cells promotes invasion and metastasis of cancer cells through activation of $\mathrm{NFkB}$ and ERK1/2 [33, 34].

Biglycan expression is increased 6-fold in CRC compared with that in normal mucosa [35]. Biglycan expression also increases with progression of CRC and liver metastasis and correlates with recurrence and reduced survival $[19,20]$. These findings support the high correlation between biglycan and CRC liver metastasis that we found in the present study.

In our data, knockdown of biglycan reduced stem cell markers and EMT phenotype. Overexpression of

\section{Stage IV}

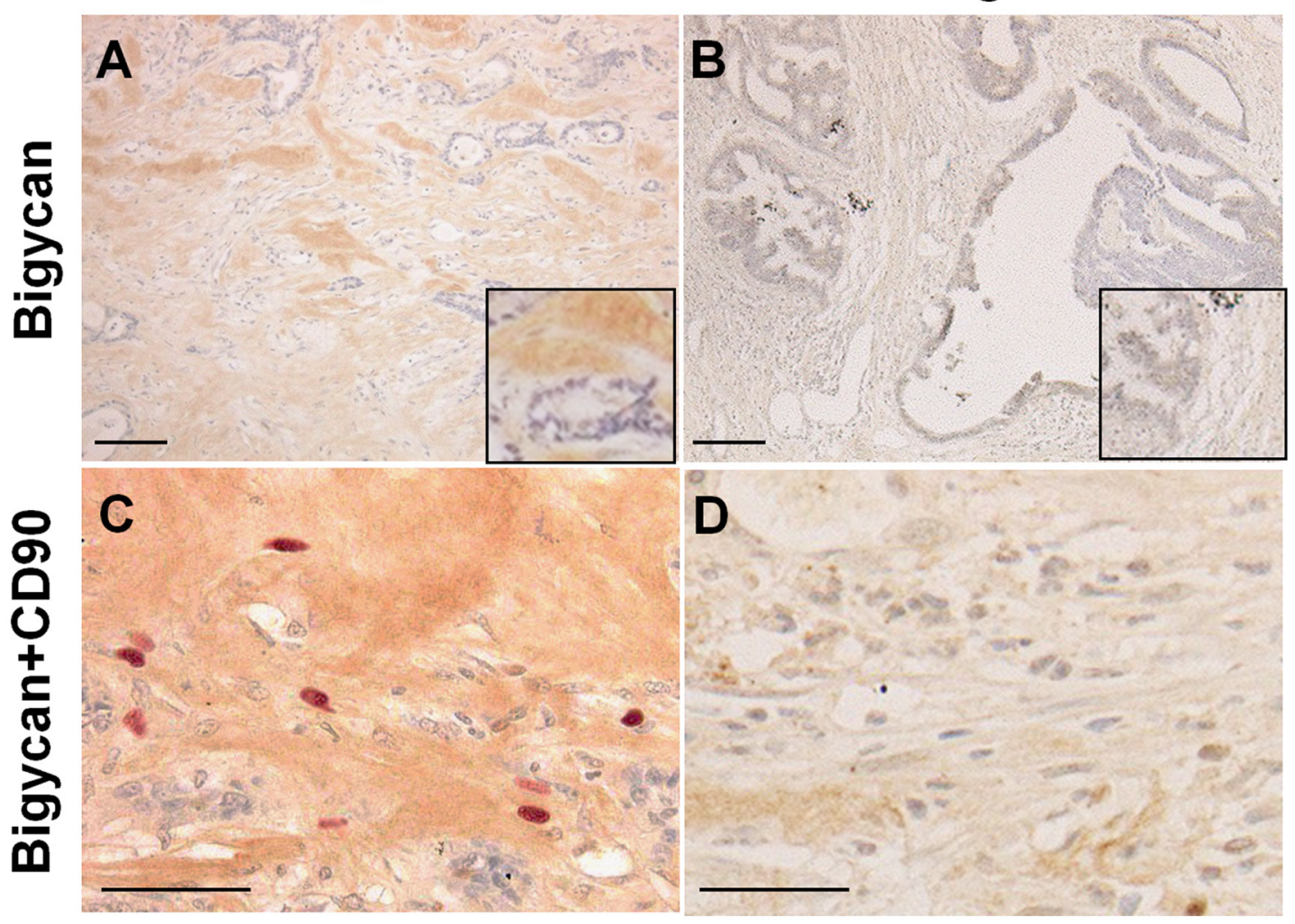

Figure 2: Expression of biglycan and CD90-positive mesenchymal stem cells in cancer stroma. (A and B) Immunohistochemistry of biglycan. (C and D) Double immunostaining of biglycan (DAB) and CD90 (Fast Red). (A and C) Stage IV colon cancer with liver metastasis. (B and D) Stage II colon cancer without metastasis. Inset, high magnification image. Scale bar: $100 \mu \mathrm{m}$. 
biglycan has been reported in spheroids of CD133-positive cancer cells [36], and overexpression in colon cancer stem cells is considered to induce anticancer drug resistance [37]. Biglycan promotes EMT in cancer cells [20, 30], and its expression involves TGF $\beta /$ Snail and TNF $\alpha / \mathrm{NF} \kappa \mathrm{B}$ signals [20, 37]. Thus, high expression of biglycan is associated with high stemness in cancer cells.

In addition, many CD90-positive MSCs were observed in the biglycan-positive myxomatous stroma. Biglycan has been reported to be involved in stemness maintenance of osteoblasts and MSCs by inhibiting their differentiation [38, 39]. It is suggested that undifferentiated MSCs accumulate in the biglycan-positive myxomatous stroma.

MSCs are implicated in many tumor-promoting roles such as angiogenesis, EMT, metastasis, drug resistance, and anti-tumoral immune suppression in cancer [40]. MSCs promote stemness of cancer cells through contact with cancer cells, secretions such as exomes, and fusion with cancer cells [41-43]. Our data suggest that the action of biglycan is mediated by cell contact between cancer cells and MSCs. Such enhancement of EMT and metastatic potential by cell contact between cancer cells and MSCs has been reported in CRC and breast cancer $[44,45]$. Upon contact between cancer cells and MSC, their interaction is suspected to occur through soluble bioactive substances and cytoplasmic and organelle interactions [46]. As this effect of MSCs on cancer cells disappears with their differentiation, it is thought that the maintenance of MSC stemness by biglycan is important for acquiring the metastatic potential of cancer cells.

In this study, biglycan overexpression was frequently observed in DM-CRC. Our data also showed that insulin induced biglycan production, with synergistic effects observed with simultaneous treatment with high concentration of glucose and pro-tumorous fatty acids, linoleic acid and elaidic acid [15, 16, 47-51]. Such high levels of insulin, glucose, and fatty acids are associated with diabetic condition. There are many reports on the overexpression of biglycan and the promotion of diabetic complications in diabetes patients. In diabetes, biglycan expression in aortic stromal cells is increased and promotes its destruction [52]. Biglycan expression is also increased in adipocytes in diabetes and is related to insulin resistance and fat inflammation [53]. In renal glomeruli,
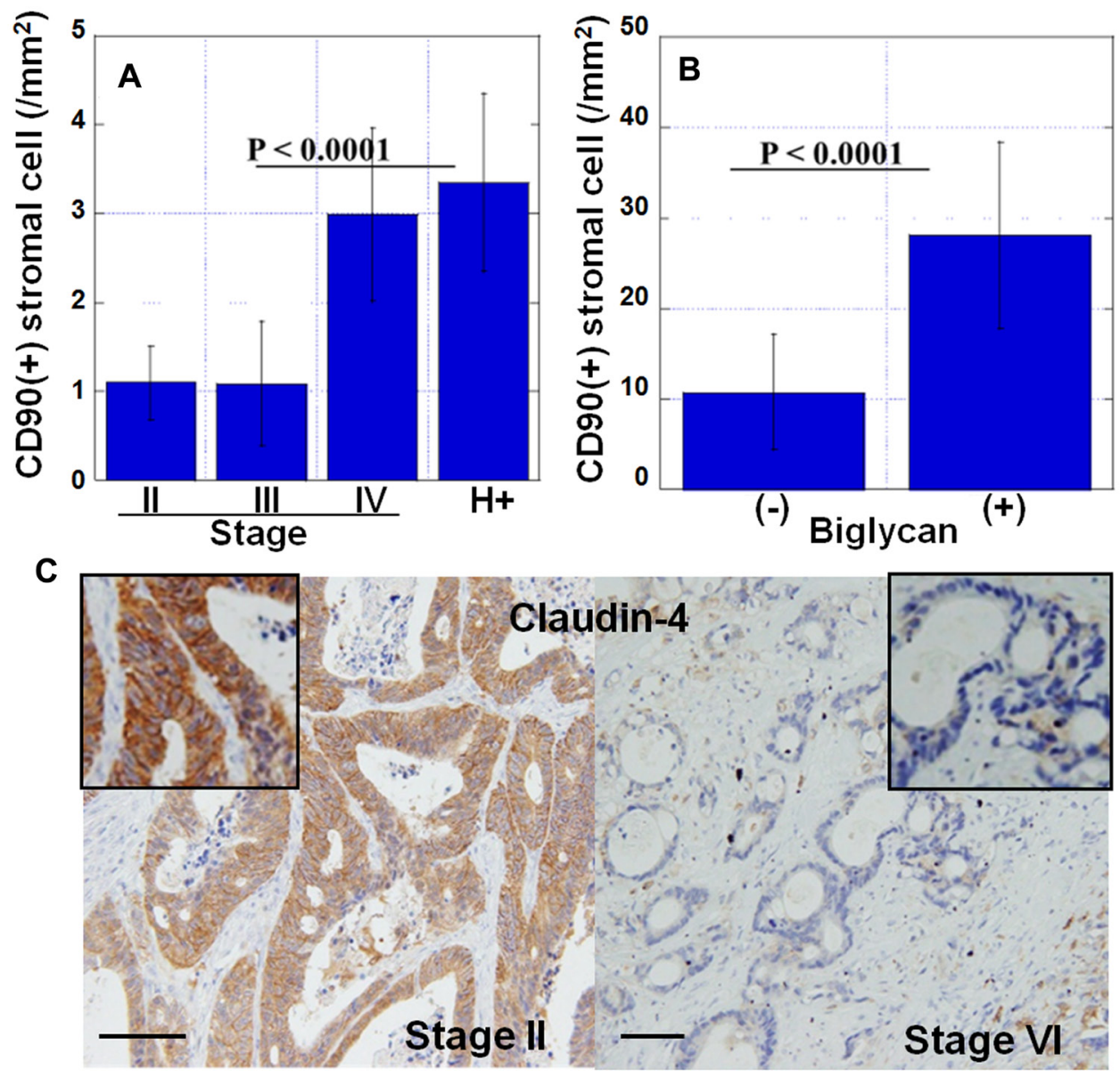

Figure 3: Features of myxomatous stroma. (A) Number of CD90-positive mesenchymal stem cells in cancer stroma at the invasive front. $\mathrm{H}+$, stage IV cases with liver metastasis. (B) Number of CD90-positive mesenchymal stem cells in biglycan-overexpressed stroma. $(+)$, biglycan overexpression positive; (-), biglycan overexpression negative. (C) Expression of claudin-4 in cancer cells in myxomatous stroma (stage IV) or usual stroma (stage II). Inset, high magnification image. Scale bar, $100 \mu \mathrm{m}$. Error bar, standard deviation. 
biglycan expression increases in diabetes and correlates with the development of diabetic nephropathy. TGF $\beta$ and PDGF have been reported to promote biglycan expression through AKT activation [54]. It is considered that biglycan expression is promoted by AKT activation even in diabetes showing hyperinsulinemia, which activates AKT $[55,56]$. On the other hand, biglycan expression is induced in tumor vascular endothelial cells by promoter demethylation [33].

In this study, diabetes was defined as a blood hemoglobin $\mathrm{A} 1 \mathrm{C}$ of $6.5 \%$ or higher at the time of CRC diagnosis. It was not possible to examine the timing of diabetes diagnosis or the treatment. It is thought that the role of diabetes on the malignant phenotype of CRC could be examined in more detail by examining the duration of diabetes, the control status of blood sugar, and the treatment content. However, blood hemoglobin A1C $6.5 \%$ at the time of CRC diagnosis was shown to be a higher blood glucose level than that at least in healthy individuals, which is considered as a potential indicator of diabetic metabolic disorder. The biglycan overexpression, which is thought to be associated with hyperinsulinemia, might also be considered as evidence of diabetes-related metabolic disorders. In future, it would be desirable to investigate the relationship with cancer, taking into account more detailed studies on diabetes, which will increase the importance of our data.

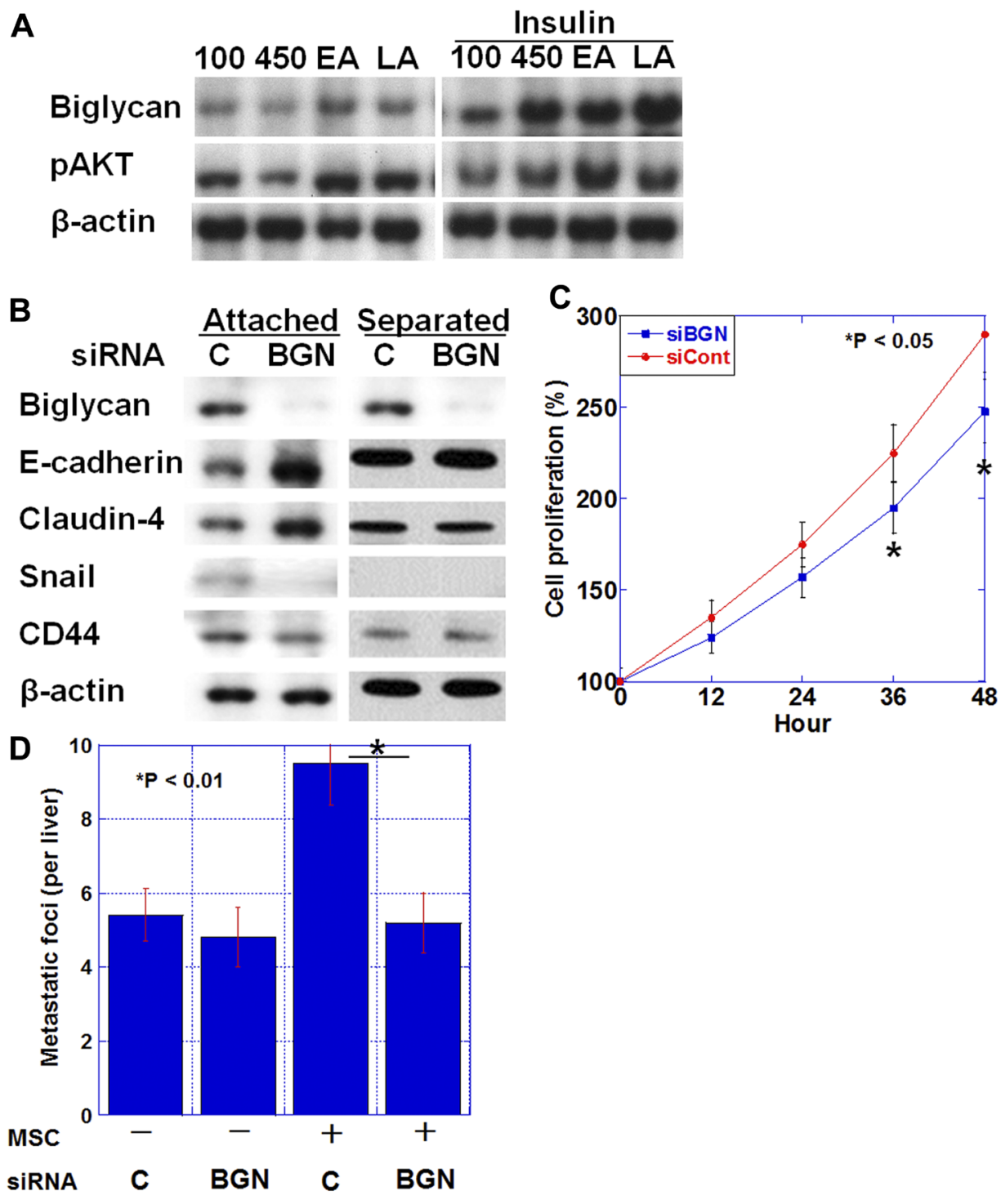

Figure 4: Biglycan expression and epithelial-mesenchymal transition (EMT). (A) Biglycan protein expression and phosphorylated AKT level in HT29 cells treated with glucose (100 mg/dL or $450 \mathrm{mg} / \mathrm{dL})$, elaidic acid $(70 \mu \mathrm{M})$ or linoleic acid (20 $\mu \mathrm{g} / \mathrm{ml})$ and/or insulin $(1 \mu \mathrm{g} / \mathrm{mL}$ ) for $24 \mathrm{~h}$. (B) Effect of biglycan (BGN) siRNA or control siRNA (C) on EMT-associated proteins (E-cadherin, Claudin-4, and Snail) and stemness-associated protein (CD44) in HT29 cells. (C) Effect of BGN siRNA (siBGN) or control siRNA (siCont) on cell proliferation of HT29 cells. (D) Number of liver metastasis of HT29 human colon cancer cells in nude mice. HT29 cells $\left(1 \times 10^{6}\right)$ pretreated with BGN siRNA or control siRNA (C) were inoculated into the spleen with or without mixed mesenchymal stem cells (MSC, $2 \times 10^{5}$ ). Error bar, standard deviation. 
In conclusion, our study suggests that diabetes promotes liver metastasis of CRC via biglycan, which induces cancer stemness and EMT from interaction with MSCs. This novel mechanism is believed to promote cancer malignancy in various cancers complicated with diabetes. The results of our study indicate the importance of diabetes management in malignant tumors in diabetes patients. And it is emphasized the significance of biglycan as a hopeful therapeutic target in malignant tumors with diabetes.

\section{MATERIALS AND METHODS}

\section{Surgical specimens}

We reviewed the pathological diagnosis and clinical data of 473 patients with surgically resected CRC, diagnosed at the Department of Molecular Pathology, Nara Medical University from 2006 to 2015. We used all cases above for analysis in this study without any selection. As written informed consent was not obtained, any identifying information was removed from the samples prior to analysis, in order to ensure strict privacy protection (unlinkable anonymization). All procedures were performed in accordance with the Ethical Guidelines for Human Genome/Gene Research enacted by the Japanese Government and were approved by the Ethics Committee of Nara Medical University (Approval Number 937).

\section{Cell lines and reagents}

HT29 human colon cancer cell line was purchased from Dainihon Pharmaceutical Co. (Tokyo, Japan). Human bone marrow-derived mesenchymal stem cell line (hMSC-BM) was purchased from Takara Bio (Kusatsu, Japan). Cells were cultured in Dulbecco's modified Eagle's medium supplemented with $10 \%$ fetal bovine serum at $37^{\circ} \mathrm{C}$ in $5 \% \mathrm{CO}_{2}$.

For the attached co-culture of HT29 and hMSC-BM cells, HT29 cells $\left(1 \times 10^{4}\right)$ were mixed with hMSC-BM cells $\left(2 \times 10^{3}\right)$ and cultured for $24 \mathrm{~h}$ in a 24-well dish. For the separated co-culture of the two cell lines, HT29 $\left(1 \times 10^{4}\right)$ cells were seeded on the bottom of a 24-well dish and hMSC-BM cells $\left(2 \times 10^{3}\right)$ were seeded in an insert with $3 \mu \mathrm{m}$-pore (Thermo Fisher Scientific, Waltham, MA, USA) for $24 \mathrm{~h}$. HT29 cells were pretreated with the siRNA for biglycan or control. HT29 cells were separated from the MSCs with EasySep Human EpCAM Positive Selection Kit II (Veritas Corp., Tokyo, Japan) and were subjected to further examination.

Linoleic acid (20 $\mu \mathrm{g} / \mathrm{mL}$, Sigma), elaidic acid (70 $\mu \mathrm{M}$, Wako Pure Chemicals, Osaka, Japan), and insulin (1 $\mu \mathrm{g} / \mathrm{mL}$, Wako) were used for cell treatments.

\section{Animals}

BALB/c nude mice (4-weeks-old, male) were purchased from SLC Japan (Shizuoka, Japan). The mice were maintained according to the institutional guidelines approved by the Committee for Animal Experimentation of Nara Medical University, in accordance with the current regulations and standards of the Ministry of Health, Labor, and Welfare (Approval number 12262).

To establish a liver metastasis model, HT29 cells $\left(1 \times 10^{6}\right)$ were inoculated into the spleen of nude mice. Then, with five mice in each group, pretreatment was carried out with siRNA for human biglycan for $24 \mathrm{~h}$ and/ or co-inoculation with hMSC-BM cells $\left(2 \times 10^{5}\right.$ cells $)$. The livers were sectioned into 2-mm-thick slices, and metastatic foci were counted using a stereomicroscope (Nikon, Tokyo, Japan).

\section{Immunohistochemistry}

Consecutive 4-mm sections were immunohistochemically stained using anti-biglycan mouse monoclonal antibody (0.2 e mon, clone 3E2, Santa Cruz Biotechnology, Santa Cruz, CA, USA) and anti-CD90 rabbit monoclonal antibody (0.2 d ant, clone EPR2959, Abcam plc., Cambridge, UK) or antiCLDN4 antibody $(0.2 \mu \mathrm{g} / \mathrm{mL}$, clone 4D3), which was established in our laboratory [57], and a previously described immunoperoxidase technique [58]. Secondary antibodies for peroxidase-conjugated mouse $\mathrm{IgG}$ and alkaline phosphatase-conjugated rabbit IgG (Medical and Biological Laboratories, Nagoya, Japan) were used at a concentration of $0.2 \mu \mathrm{g} / \mathrm{mL}$. Tissue sections were color-developed with diamine benzidine hydrochloride (DAKO, Glastrup, Denmark) for biglycan and with fast red (CosmoBio, Tokyo, Japan) for CD90. Slides were counterstained with Meyer's hematoxylin (Sigma). Overexpression of biglycan was determined when the expression was stronger than that of biglycan in normal colon mucosa. For evaluation of CD90 immunostaining, number of positive cells was counted in 500 cells. For negative control, non-immunized rat IgG (Santa Cruz) was used as a primary antibody. Positive straining for biglycan was defined as stronger staining than that in normal colonic epithelium. We used placental tissue as a positive control.

\section{Immunoblot analysis}

Whole-cell lysates were prepared as previously described [59]. Lysates $(20 \mu \mathrm{g})$ were subjected to immunoblot analysis using SDS-PAGE (12.5\%), followed by electrotransfer onto nitrocellulose filters. The filters were incubated with primary antibodies, followed by peroxidase-conjugated IgG antibodies (Medical and Biological Laboratories). Anti-tubulin antibody was used to assess the protein levels loaded per lane (Oncogene Research Products, Cambridge, MA, USA). The immune complex was visualized using an Enhanced Chemiluminescence Western-blot detection system 
(Amersham, Aylesbury, UK). Antibodies for biglycan (Santa Cruz), phosphorylated AKT (phosphoSer473, Proteintech Group Inc. Rosemont, IL, USA), E-cadherin (DAKO), CLDN4 (clone 4D3) [57], Snail (Biorbyt, St Louis, MO, USA), and CD44 (Abcam) were used as primary antibodies. $\beta$-actin, detected by antibody (Abcam), was used as the loading control.

\section{Short interfering RNA (siRNA) assay}

FlexiTube siRNAs targeting human biglycan gene $(B G N)$ were purchased from Santa Cruz Biotechnology. AllStars Negative Control siRNA (Qiagen) was used as a control. Cells were transfected with $50 \mathrm{nM}$ siRNA using Lipofectamine 2000 (Invitrogen, Carlsbad, CA, USA), according to the manufacturer's instructions.

\section{Statistical analysis}

Statistical significance was calculated using a twotailed Fisher's exact test, an ordinary ANOVA, and InStat software (GraphPad, Los Angeles, CA, USA). Multiple regression analysis was performed using EZR program [60]. A two-sided $P$ value of $<0.05$ was considered to indicate statistical significance.

\section{ACKNOWLEDGMENTS AND FUNDING}

This work was supported by MEXT KAKENHI Grant Numbers 19K16564 (RFT), 17K19923 (HK), and 18K16671 (SK). The authors thank Ms. Tomomi Masutani for expert assistance with the preparation of this manuscript.

\section{CONFLICTS OF INTEREST}

The authors have no conflicts of interest to declare.

\section{REFERENCES}

1. Federation ID. International Diabetes Federation Diabetes Atlas. 2019

2. Nicolucci A. Epidemiological aspects of neoplasms in diabetes. Acta Diabetol. 2010; 47:87-95. https://doi. org/10.1007/s00592-010-0187-3. [PubMed]

3. Lin CM, Huang HL, Chu FY, Fan HC, Chen HA, Chu DM, Wu LW, Wang CC, Chen WL, Lin SH, Ho SY. Association between Gastroenterological Malignancy and Diabetes Mellitus and Anti-Diabetic Therapy: A Nationwide, Population-Based Cohort Study. PLoS One. 2015; 10:e0125421. https://doi.org/10.1371/journal.pone.0125421. [PubMed]

4. Herrigel DJ, Moss RA. Diabetes mellitus as a novel risk factor for gastrointestinal malignancies. Postgrad Med. 2014; 126:106-118. https://doi.org/10.3810/pgm.2014.10.2825. [PubMed]
5. Goto A, Noto H, Noda M, Ueki K, Kasuga M, Tajima N, Ohashi K, Sakai R, Tsugane S, Hamajima N, Tajima K, Imai K, Nakagama H. Report of the Japan diabetes society/ Japanese cancer association joint committee on diabetes and cancer, Second report. Cancer Sci. 2016; 107:369-371. https://doi.org/10.1111/cas.12889. [PubMed]

6. Kasuga M, Ueki K, Tajima N, Noda M, Ohashi K, Noto H, Goto A, Ogawa W, Sakai R, Tsugane S, Hamajima N, Nakagama H, Tajima K, et al. Report of the Japan Diabetes Society/Japanese Cancer Association Joint Committee on Diabetes and Cancer. Cancer Sci. 2013; 104:965-976. https://doi.org/10.1111/cas.12203. [PubMed]

7. Huxley RR, Ansary-Moghaddam A, Clifton P, Czernichow S, Parr CL, Woodward M. The impact of dietary and lifestyle risk factors on risk of colorectal cancer: a quantitative overview of the epidemiological evidence. Int J Cancer. 2009; 125:171-180. https://doi.org/10.1002/ ijc.24343. [PubMed]

8. Larsson SC, Orsini N, Wolk A. Diabetes mellitus and risk of colorectal cancer: a meta-analysis. J Natl Cancer Inst. 2005; 97:1679-1687. https://doi.org/10.1093/jnci/dji375. [PubMed]

9. He Q, Zhang H, Yao S, Zhu D, Lv D, Cui P, Xu Y. A study on relationship between metabolic syndrome and colorectal cancer. J BUON. 2018; 23:1362-1368. [PubMed]

10. Abdel-Rahman O. Impact of diabetes comorbidity on the efficacy and safety of FOLFOX first-line chemotherapy among patients with metastatic colorectal cancer: a pooled analysis of two phase-III studies. Clin Transl Oncol. 2019; 21:512-518. https://doi.org/10.1007/s12094-018-1939-8. [PubMed]

11. Lu CC, Chu PY, Hsia SM, Wu CH, Tung YT, Yen GC. Insulin induction instigates cell proliferation and metastasis in human colorectal cancer cells. Int J Oncol. 2017; 50:736744. https://doi.org/10.3892/ijo.2017.3844. [PubMed]

12. Yang J, Nishihara R, Zhang X, Ogino S, Qian ZR. Energy sensing pathways: Bridging type 2 diabetes and colorectal cancer? J Diabetes Complications. 2017; 31:1228-1236. https://doi.org/10.1016/j.jdiacomp.2017.04.012. [PubMed]

13. Wojciechowska J, Krajewski W, Bolanowski M, Krecicki T, Zatonski T. Diabetes and Cancer: a Review of Current Knowledge. Exp Clin Endocrinol Diabetes. 2016; 124:263275. https://doi.org/10.1055/s-0042-100910. [PubMed]

14. Chhipa AS, Borse SP, Baksi R, Lalotra S, Nivsarkar M. Targeting receptors of advanced glycation end products (RAGE): Preventing diabetes induced cancer and diabetic complications. Pathol Res Pract. 2019; 215:152643. https:// doi.org/10.1016/j.prp.2019.152643. [PubMed]

15. Shimomoto T, Luo Y, Ohmori H, Chihara Y, Fujii K, Sasahira T, Denda A, Kuniyasu H. Advanced glycation end products (AGE) induce the receptor for AGE in the colonic mucosa of azoxymethane-injected Fischer 344 rats fed with a highlinoleic acid and high-glucose diet. J Gastroenterol. 2012; 47:1073-1083. https://doi.org/10.1007/s00535-012-0572-5. [PubMed] 
16. Ohmori H, Luo Y, Fujii K, Sasahira T, Shimomoto T, Denda A, Kuniyasu H. Dietary linoleic acid and glucose enhances azoxymethane-induced colon cancer and metastases via the expression of high-mobility group box 1. Pathobiology. 2010; 77:210-217. https://doi.org/10.1159/000296305. [PubMed]

17. Shimomoto T, Ohmori H, Luo Y, Chihara Y, Denda A, Sasahira T, Tatsumoto N, Fujii K, Kuniyasu H. Diabetesassociated angiotensin activation enhances liver metastasis of colon cancer. Clin Exp Metastasis. 2012; 29:915-925. https://doi.org/10.1007/s10585-012-9480-6. [PubMed]

18. Ye F, Chen Y, Xia L, Lian J, Yang S. Aldolase A overexpression is associated with poor prognosis and promotes tumor progression by the epithelial-mesenchymal transition in colon cancer. Biochem Biophys Res Commun. 2018; 497:639-645. https://doi.org/10.1016/j. bbrc.2018.02.123. [PubMed]

19. Qian Z, Zhang G, Song G, Shi J, Gong L, Mou Y, Han Y. Integrated analysis of genes associated with poor prognosis of patients with colorectal cancer liver metastasis. Oncotarget. 2017; 8:25500-25512. https://doi.org/10.18632/ oncotarget.16064. [PubMed]

20. Li H, Zhong A, Li S, Meng X, Wang X, Xu F, Lai M. The integrated pathway of TGF $\beta /$ Snail with $\mathrm{TNF} \alpha / \mathrm{NF} \kappa \mathrm{B}$ may facilitate the tumor-stroma interaction in the EMT process and colorectal cancer prognosis. Sci Rep. 2017; 7:4915. https://doi.org/10.1038/s41598-017-05280-6. [PubMed]

21. Fujimoto Y, Nakanishi Y, Sekine S, Yoshimura K, Akasu T, Moriya Y, Shimoda T. CD10 expression in colorectal carcinoma correlates with liver metastasis. Dis Colon Rectum. 2005; 48:1883-1889. https://doi.org/10.1007/ s10350-005-0141-6. [PubMed]

22. Fong Y, Kemeny N, Paty P, Blumgart LH, Cohen AM. Treatment of colorectal cancer: hepatic metastasis. Semin Surg Oncol. 1996; 12:219-252. https://doi. org/10.1002/(SICI)1098-2388(199607/08)12:4<219::AID$\underline{\text { SSU3 }>3.0 . C O ; 2-8}$. [PubMed]

23. Halper J. Advances in the use of growth factors for treatment of disorders of soft tissues. Adv Exp Med Biol. 2014; 802:59-76. https://doi.org/10.1007/978-94-007-7893-1_5. [PubMed]

24. Karamanos NK. Matrix pathobiology-central roles for proteoglycans and heparanase in health and disease. FEBS J. 2017; 284:7-9. https://doi.org/10.1111/febs.13945. [PubMed]

25. Roedig H, Nastase MV, Wygrecka M, Schaefer L. Breaking down chronic inflammatory diseases: the role of biglycan in promoting a switch between inflammation and autophagy. FEBS J. 2019; 286:2965-2979. https://doi.org/10.1111/febs.14791. [PubMed]

26. Sun H, Wang X, Zhang Y, Che X, Liu Z, Zhang L, Qiu C, Lv Q, Jiang J. Biglycan enhances the ability of migration and invasion in endometrial cancer. Arch Gynecol Obstet. 2016; 293:429-438. https://doi.org/10.1007/s00404-0153844-5. [PubMed]
27. Wang B, Li GX, Zhang SG, Wang Q, Wen YG, Tang HM, Zhou CZ, Xing AY, Fan JW, Yan DW, Qiu GQ, Yu ZH, Peng $Z H$. Biglycan expression correlates with aggressiveness and poor prognosis of gastric cancer. Exp Biol Med (Maywood). 2011; 236:1247-1253. https://doi.org/10.1258/ ebm.2011.011124. [ubMed]

28. Hu L, Zang MD, Wang HX, Li JF, Su LP, Yan M, Li C, Yang QM, Liu BY, Zhu ZG. Biglycan stimulates VEGF expression in endothelial cells by activating the TLR signaling pathway. Mol Oncol. 2016; 10:1473-1484. https://doi.org/10.1016/j.molonc.2016.08.002. [PubMed]

29. Jacobsen F, Kraft J, Schroeder C, Hube-Magg C, Kluth M, Lang DS, Simon R, Sauter G, Izbicki JR, Clauditz TS, Luebke AM, Hinsch A, Wilczak W, et al. Up-regulation of Biglycan is Associated with Poor Prognosis and PTEN Deletion in Patients with Prostate Cancer. Neoplasia. 2017; 19:707-715. https://doi.org/10.1016/j.neo.2017.06.003. [PubMed]

30. Schulz GB, Grimm T, Sers C, Riemer P, Elmasry M, Kirchner T, Stief CG, Karl A, Horst D. Prognostic value and association with epithelial-mesenchymal transition and molecular subtypes of the proteoglycan biglycan in advanced bladder cancer. Urol Oncol. 2019; 37:530.e9-e18. https://doi.org/10.1016/j.urolonc.2019.05.011. [PubMed]

31. Appunni S, Anand V, Khandelwal M, Gupta N, Rubens M, Sharma A. Small Leucine Rich Proteoglycans (decorin, biglycan and lumican) in cancer. Clin Chim Acta. 2019; 491:1-7. https://doi.org/10.1016/j.cca.2019.01.003. [PubMed]

32. Andrlova H, Mastroianni J, Madl J, Kern JS, Melchinger W, Dierbach H, Wernet F, Follo M, Technau-Hafsi K, Has C, Rao Mittapalli V, Idzko M, Herr R, et al. Biglycan expression in the melanoma microenvironment promotes invasiveness via increased tissue stiffness inducing integrinbeta1 expression. Oncotarget. 2017; 8:42901-42916. https://doi.org/10.18632/oncotarget.17160. [PubMed]

33. Maishi N, Ohba Y, Akiyama K, Ohga N, Hamada J, NagaoKitamoto H, Alam MT, Yamamoto K, Kawamoto T, Inoue N, Taketomi A, Shindoh M, Hida Y, Hida K. Tumour endothelial cells in high metastatic tumours promote metastasis via epigenetic dysregulation of biglycan. Sci Rep. 2016; 6:28039. https://doi.org/10.1038/srep28039. [PubMed]

34. Maishi N, Hida K. Tumor endothelial cells accelerate tumor metastasis. Cancer Sci. 2017; 108:1921-1926. https://doi. org/10.1111/cas.13336. [ [ PubMed]

35. Suhovskih AV, Aidagulova SV, Kashuba VI, Grigorieva EV. Proteoglycans as potential microenvironmental biomarkers for colon cancer. Cell Tissue Res. 2015; 361:833-844. https://doi.org/10.1007/s00441-015-2141-8. [PubMed]

36. Fang DD, Kim YJ, Lee CN, Aggarwal S, McKinnon K, Mesmer D, Norton J, Birse CE, He T, Ruben SM, Moore PA. Expansion of CD133(+) colon cancer cultures retaining stem cell properties to enable cancer stem cell target discovery. Br J Cancer. 2010; 102:1265-1275. https://doi. org/10.1038/sj.bjc.6605610. [PubMed] 
37. Liu B, Xu T, Xu X, Cui Y, Xing X. Biglycan promotes the chemotherapy resistance of colon cancer by activating NF-kappaB signal transduction. Mol Cell Biochem. 2018; 449:285-294. https://doi.org/10.1007/s11010-018-3365-1. [PubMed]

38. Bi Y, Nielsen KL, Kilts TM, Yoon A, A Karsdal M, Wimer HF, Greenfield EM, Heegaard AM, Young MF. Biglycan deficiency increases osteoclast differentiation and activity due to defective osteoblasts. Bone. 2006; 38:778-786. https://doi.org/10.1016/j.bone.2005.11.005. [PubMed]

39. Chen XD, Dusevich V, Feng JQ, Manolagas SC, Jilka RL. Extracellular matrix made by bone marrow cells facilitates expansion of marrow-derived mesenchymal progenitor cells and prevents their differentiation into osteoblasts. J Bone Miner Res. 2007; 22:1943-1956. https://doi.org/10.1359/ jbmr.070725. [PubMed]

40. Timaner M, Tsai KK, Shaked Y. The multifaceted role of mesenchymal stem cells in cancer. Semin Cancer Biol. 2020; 60:225-237. https://doi.org/10.1016/j.semcancer.2019.06.003. [PubMed]

41. Melzer C, von der Ohe J, Lehnert H, Ungefroren H, Hass R. Cancer stem cell niche models and contribution by mesenchymal stroma/stem cells. Mol Cancer. 2017; 16:28. https://doi.org/10.1186/s12943-017-0595-x. [PubMed]

42. Xu MH, Gao X, Luo D, Zhou XD, Xiong W, Liu GX. EMT and acquisition of stem cell-like properties are involved in spontaneous formation of tumorigenic hybrids between lung cancer and bone marrow-derived mesenchymal stem cells. PLoS One. 2014; 9:e87893. https://doi.org/10.1371/journal. pone.0087893. [PubMed]

43. Kuhn NZ, Tuan RS. Regulation of stemness and stem cell niche of mesenchymal stem cells: implications in tumorigenesis and metastasis. J Cell Physiol. 2010; 222:268-277. https://doi.org/10.1002/jcp.21940. [PubMed]

44. Takigawa H, Kitadai Y, Shinagawa K, Yuge R, Higashi Y, Tanaka S, Yasui W, Chayama K. Mesenchymal Stem Cells Induce Epithelial to Mesenchymal Transition in Colon Cancer Cells through Direct Cell-to-Cell Contact. Neoplasia. 2017; 19:429-438. https://doi.org/10.1016/j. $\underline{\text { neo.2017.02.010. }}$ [ [PubMed]

45. Martin FT, Dwyer RM, Kelly J, Khan S, Murphy JM, Curran C, Miller N, Hennessy E, Dockery P, Barry FP, O'Brien T, Kerin MJ. Potential role of mesenchymal stem cells (MSCs) in the breast tumour microenvironment: stimulation of epithelial to mesenchymal transition (EMT). Breast Cancer Res Treat. 2010; 124:317-326. https://doi. org/10.1007/s10549-010-0734-1. [PubMed]

46. Trivanovic D, Krstic J, Jaukovic A, Bugarski D, Santibanez JF. Mesenchymal stromal cell engagement in cancer cell epithelial to mesenchymal transition. Dev Dyn. 2018; 247:359-367. https://doi.org/10.1002/dvdy.24583. [PubMed]

47. Fujii K, Luo Y, Fujiwara-Tani R, Kishi S, He S, Yang $\mathrm{S}$, Sasaki T, Ohmori H, Kuniyasu H. Pro-metastatic intracellular signaling of the elaidic trans fatty acid. Int J Oncol. 2017; 50:85-92. https://doi.org/10.3892/ ijo.2016.3797. [PubMed]
48. Kishi S, Fujiwara-Tani R, Luo Y, Kawahara I, Goto K, Fujii K, Ohmori H, Nakashima C, Sasaki T, Kuniyasu H. Prometastatic signaling of the trans fatty acid elaidic acid is associated with lipid rafts. Oncol Lett. 2018; 15:4423-4426. https://doi.org/10.3892/ol.2018.7817. [PubMed]

49. Kusuoka O, Fujiwara-Tani R, Nakashima C, Fujii K, Ohmori H, Mori T, Kishi S, Miyagawa Y, Goto K, Kawahara I, Kuniyasu H. Intermittent calorie restriction enhances epithelial-mesenchymal transition through the alteration of energy metabolism in a mouse tumor model. Int J Oncol. 2018; 52:413-423. https://doi.org/10.3892/ ijo.2017.4229. [PubMed]

50. Ohmori H, Fujii K, Kadochi Y, Mori S, Nishiguchi Y, Fujiwara R, Kishi S, Sasaki T, Kuniyasu H. Elaidic Acid, a Trans-Fatty Acid, Enhances the Metastasis of Colorectal Cancer Cells. Pathobiology. 2017; 84:144-151. https://doi. org/10.1159/000449205. [PubMed]

51. Tanabe E, Kitayoshi M, Fujii K, Ohmori H, Luo Y, Kadochi Y, Mori S, Fujiwara R, Nishiguchi Y, Sasaki T, Kuniyasu H. Fatty acids inhibit anticancer effects of 5-fluorouracil in mouse cancer cell lines. Oncol Lett. 2017; 14:681-686. https://doi.org/10.3892/ol.2017.6190. [PubMed]

52. Barth M, Selig JI, Klose S, Schomakers A, Kiene LS, Raschke S, Boeken U, Akhyari P, Fischer JW, Lichtenberg A. Degenerative aortic valve disease and diabetes: Implications for a link between proteoglycans and diabetic disorders in the aortic valve. Diab Vasc Dis Res. 2019; 16:254-269. https:// doi.org/10.1177/1479164118817922. [PubMed]

53. Kim J, Lee SK, Shin JM, Jeoun UW, Jang YJ, Park HS, Kim JH, Gong GY, Lee TJ, Hong JP, Lee YJ, Heo YS. Enhanced biglycan gene expression in the adipose tissues of obese women and its association with obesity-related genes and metabolic parameters. Sci Rep. 2016; 6:30609. https://doi. org/10.1038/srep30609. [PubMed]

54. Osman N, Getachew R, Burch M, Lancaster G, Wang R, Wang $H$, Zheng W, Little PJ. TGF- $\beta$ stimulates biglycan core protein synthesis but not glycosaminoglycan chain elongation via Akt phosphorylation in vascular smooth muscle. Growth Factors. 2011; 29:203-210. https://doi.or $\mathrm{g} / 10.3109 / 08977194.2011 .615747$. [PubMed]

55. Yang Q, Vijayakumar A, Kahn BB. Metabolites as regulators of insulin sensitivity and metabolism. Nat Rev Mol Cell Biol. 2018; 19:654-672. https://doi.org/10.1038/ s41580-018-0044-8. [PubMed]

56. Sun S, Tan P, Huang X, Zhang W, Kong C, Ren F, Su X. Ubiquitinated CD36 sustains insulin-stimulated Akt activation by stabilizing insulin receptor substrate 1 in myotubes. J Biol Chem. 2018; 293:2383-2394. https://doi. org/10.1074/jbc.M117.811471. [PubMed]

57. Kuwada M, Chihara Y, Luo Y, Li X, Nishiguchi Y, Fujiwara R, Sasaki T, Fujii K, Ohmori H, Fujimoto K, Kondoh M, Kuniyasu H. Pro-chemotherapeutic effects of antibody against extracellular domain of claudin-4 in bladder cancer. Cancer Lett. 2015; 369:212-21. https://doi.org/10.1016/j.canlet.2015.08.019. [PubMed] 
58. Kuniyasu H, Yano S, Sasaki T, Sasahira T, Sone S, Ohmori H. Colon cancer cell-derived high mobility group 1/ amphoterin induces growth inhibition and apoptosis in macrophages. Am J Pathol. 2005; 166:751-760. https://doi. org/10.1016/S0002-9440(10)62296-1. [PubMed]

59. Kuniyasu H, Oue N, Wakikawa A, Shigeishi H, Matsutani N, Kuraoka K, Ito R, Yokozaki H, Yasui W. Expression of receptors for advanced glycation end-products (RAGE) is closely associated with the invasive and metastatic activity of gastric cancer. J Pathol. 2002; 196:163-170. https://doi. org/10.1002/path.1031. [PubMed]

60. Kanda Y. Investigation of the freely available easy-touse software 'EZR' for medical statistics. Bone Marrow Transplant. 2013; 48:452-458. https://doi.org/10.1038/ bmt.2012.244. [PubMed]

61. Gospodarowicz M, Wittekind C, Sobin LH. UICC TNM Classification of malignant tumours. New York: John Wiley \& Sons, Inc.; 2009
62. Japanese Society for Cancer of the Colon and Rectum. Japanese Classification of Colorectal, Appendiceal, and Anal Carcinoma. Kyoto: Kanehara \& Co. Ltd.; 2019.

63. Kuniyasu H, Yasui W, Shinohara H, Yano S, Ellis LM, Wilson MR, Bucana CD, Rikita T, Tahara E, Fidler IJ. Induction of angiogenesis by hyperplastic colonic mucosa adjacent to colon cancer. Am J Pathol. 2000; 157:15231535. https://doi.org/10.1016/S0002-9440(10)64790-6. [PubMed]

64. Kuniyasu H, Oue N, Shigeishi H, Ito R, Kato Y, Yokozaki $\mathrm{H}$, Yasui W. Prospective study of Ki-67 labeling index in the mucosa adjacent to cancer as a marker for colorectal cancer metastasis. J Exp Clin Cancer Res. 2001; 20:543-548. [PubMed] 